\title{
Sosyal Medyada Kitle Çeviri Üzerine Bir Araştırma
}

\author{
EZGi KESKIN GAGA* \\ ezgi.keskin@sfl.bau.edu.tr
}

Özet: Bu araştırma, Türkiye'de "Sosyal Medya Çevirileri” örneğinde yaygınlaşan ve giderek popüler bir eylem haline geldiği düşünülen "Kitle Çeviri (crowdsourcing translation)" yöntemini inceleme amacını taşımaktadır. Çalışmanın temel sorunsalları; kitle çeviri yöntemiyle kitlesel üretimi yapılan çeviri eyleminin giderek popüler kültür ürünü haline gelmesi, popüler zeminde üretilen bu çevirilerin kalitesi, çeviriyi üreten çevirmenlerin kimliğidir. Araştırma kapsamında sosyal medya sitelerinden Facebook incelenerek Facebook’un Türkçeye çevrilmesine katkıda bulunan gönüllü çevirmenlere 16 soruluk anket uygulanmıştır. Araştırma sonucu yapılan değerlendirmeler uygulanan anket çerçevesinde ortaya çıkmıştır. Değerlendirmeler yalnızca anket uygulanan grupla sınırlıdır. Araştırmanın ilk bölümünde kitle çevirinin popüler kültürdeki konumu değerlendirilmiş, ikinci bölümde sosyal medya sitesi Facebook örneğinde "kitle çeviri" olgusu incelenmiştir. Araştırmanın sonunda, kitle çeviri yöntemiyle kitlesel üretimi yapılan çeviri eyleminin nasıl bir dönüşüm içine girdiği izlenmektedir. Çeviri eyleminin giderek popüler kültür ürünü haline geldiği görülmektedir.

Anahtar Kelimeler: Kitle çeviri, Sosyal medya çevirisi, Gönüllü çeviri/çevirmen.

\section{Giriş}

İnternet yaygınlaştığından bu yana kullanıcılarının alışkanlıklarının giderek değiştiği görülmektedir. İnternet, gündelik yaşamı büyük oranda etkilemekte, iletişim adına onlara sayısız seçenek sunmaktadır. Web 2.0 araçları sayesinde, artık bir tıkla kolayca bankacılık işlemleri yapılabilmekte yüzlerce kilometre ötedeki kişilerle iletişime geçilebilmektedir. Gelişen internet kullanımı sayesinde dünya hızla küreselleşmekte, sınırlar ortadan kalkmakta ve mesafeler kısalmaktadır. Artık insanlar kısa sürede bilgiye ulaşmayı ve onu paylaşmayı dilemektedir. Bu süreçte dilsel farklıklar ön plana çıksa da yine aynı hızla dil engeli ortadan kaldırılmaya çalışılmaktadır. Şüphesiz; bölgelerin birbirleriyle iletişim halinde olabilmeleri ancak çeviri yoluyla mümkündür. Öte yandan zaman baskısı çeviri eyleminin kısa sürede yapılmasını zorunlu kılmaktadır. ${ }^{1}$ Dolayısıyla çeviri eyleminin de içinde bulunduğu şartlara göre evirildiği, üretici ve kullanıcılarının taleplerine göre dönüştüğü gözlemlenmektedir. Bu yeni ortamda çeviri aktivitelerinin gerçekleştirilme formları değiștiği, özellikle çeviri belleği, bilgisayar destekli çeviri yazılımı ya da web temelli bilgisayarlı çeviri hizmetleri

\footnotetext{
* Okutman, Bahçeşehir Üniversitesi, Yabancı Diller Yüksekokulu.

1 Micheal Cronin, "Globalization and Translation" Handbook of Translation Studies, Gambier ve Van Luc Doorslaer. Amsterdam: John Benjamins Publishing, 2010, s.134.
} 
gibi çeviri teknolojilerinin gelişiminin arttığı görülmektedir. ${ }^{2}$ Bu formlara ek olarak "kitle çeviri (crowdsourcing translation)" son zamanlarda işverenler ve aynı zamanda müşteriler tarafından en rağbet gören çeviri yöntemi olarak dikkat çekmektedir. İlk kez, Jeff Howe tarafindan öne sürülen "Crowdsourcing” uygulaması işverenin işin büyük bir kısmını küçük parçalar halinde büyük bir gruba paylaştırarak, ürünün kitlesel üretimini yaptırdığı, karşılığında hiçbir ödeme yapmadığı bir sistemdir. İş, tamamen gönüllülük esasına göre yapılmaktadır. ${ }^{3}$ Bu uygulamanın birçok alanda olduğu gibi çeviri alanında da, başta sosyal medya sitelerinin çevirilerinde kullanıldığı bilinmektedir (bkz. Facebook, Twitter, vb.). Bu yöntemle bu sitelere üye olan kullanıcılar gönüllü olarak çeviri yapmaktadır. Üyelerin çeviri eylemini gerçekleştirmeleri için adı geçen bu siteler çeviri uygulamasının reklamını yaparak, üyelerini bu eyleme davet etmektedirler. Bu sayede, hem çeviri edimi popüler bir zemine taşınarak kitlesel üretim yapılmakta; hem kısa sürede dilsel iletişim sağlanmakta, hem de işveren ekonomik anlamda kâr etmektedir. Buna karşın çevirmen kimliğinin bu yöntemle birlikte bulanık bir biçime büründüğü gözlenmektedir. Çeviriyi gerçekleştiren eyleyicilerin kim olduğu belirsizleşmektedir.

Bu çalışmada, kitle çeviri yöntemiyle çeviri eyleminin nasıl bir dönüşüm içine girdiği değerlendirilmeye çalışılacaktır. Bu amaçla kitle çeviri yöntemiyle kitlesel üretimi yapılan çeviri eyleminin giderek nasıl bir popüler kültür ürünü haline geldiği, popüler zeminde üretilen bu çevirilerin kalitesi, çeviriyi üreten çevirmenlerin kimliği incelenecektir. Araştırmanın ilk bölümünde, kitle çevirinin popüler kültürdeki konumu değerlendirilecek; ikinci bölümde sosyal medya sitesi Facebook örneğinde "kitle çeviri" olgusu incelenecektir. Bu doğrultuda, Facebook'un Türkçeye çevrilmesine katkıda bulunan gönüllü çevirmenlere 16 soruluk anket uygulanmıştır. Değerlendirmeler, anket sonuçları çerçevesinde yapilacaktır.

\section{Popüler Kültür ve Kitle Çeviri}

\section{Popüler Kültür Kavramı}

Popüler kültür, en geniş ve kabul gören tanımıyla gündelik hayatın kültürü olarak tanımlanabilir. Halk ve çoğunluk terimlerini içerdiği için belli bir grubun kültürel edimleri değil, «herkesin değilse bile hemen herkesin» paylaştığı kültürel gerçekliği ifade eder. Dolayısıyla bu kavramın dinden edebiyata, spordan müziğe, sinemadan bilime, ekonomiden siyasete; hatta anarşizme kadar günlük hayatın gerçekleştiği bütün alanları içine aldığı görülmektedir. ${ }^{4}$

Popüler kültür, kitleler üzerindeki etkisi olumlu ya da olumsuz olsun, bir biçimde ideoloji ürettiği ve bu ideolojik içeriği kitlelerin bilinçaltına yerleştirdiği düşünülmektedir. Neredeyse tamamen bir üretim ve çoğunlukla da tüketim kültürüdür. Kendini kitle iletişim araçlarıyla var eder ve varlığını yine onlar üzerinden sürdürür. ${ }^{5}$

2 Cronin, "Globalization and Translation", s.135.

3 Jeff Howe, Wired,14 Temmuz 2006, www.wired.com/wired/archive/14.06/crowds.html (Erişim 30 Kasım,2014). 4 Alim Arlı ve Güney Çeğin, “İdeoloji Kavramının aşınması ve Pierre Bourdieu’nün Kuramsal Seçenekleri”, Doğu Batı Dergisi, 28 (2004), s.163.

5 Arlı ve Çeğin, “İdeoloji Kavramının Aşınması...”, s.163. 
Dwight Macdonald üretimin salt ve doğrudan kitle tüketimi amaçlı olmasından ötürü popüler kültür kavramını kitle kültürü (mass culture) olarak tanımlamanın daha doğru olacağını savunur. Kitle kültürünü pazar için toplu üretim yapan kültür olarak niteler. ${ }^{6} \mathrm{Bu}$ doğrultuda popüler kültürün kapitalizmle ilintili bir kavram olduğu açıkça görülmektedir. Modern dönemin zaman anlayışındaki, tekno kapitalizmin "her şeyi daha kısa zamanda gerçekleştir" ilkesi tüm insanlık deneyimlerini "şimdiye" sıkıştırmaktadır. Böylece modern zaman "şimdiyi” eskisinden daha olanaklı bir biçime dönüştürürken, geçmişi ve geleceği de olanaksız kılmaktadır. ${ }^{7}$ Bu noktada popüler kültürün tam da yaşanılan ana hizmet ettiği görülmektedir. Kitleler, geçmişi ve geleceği düşünmeden, sunulan ürünleri hemen şimdi tüketmelidir.

Hannah Arendt'e göre, kitle toplumunun ihtiyacı kültür değil, eğlencedir ve eğlence endüstrisinin sunduğu eşyalar toplum tarafından tıpkı diğer tüketim metaları gibi tüketilirler. Eğlenmek için gerek duyulan ürünler, ekmek, su kadar zorunlu olmasa bile, toplumun yaşam sürecine hizmet ederler ve vakit öldürmeye yararlar. ${ }^{8}$

Popüler kültürün belirleyicilerinden boş zaman olgusu daha çok tüketmek ve eğlenmek üzerine kurulmuştur. ${ }^{9}$ Hannah Arendt, vakit öldürmekle geçirilen boş zamanın, serbest zaman olmadığını ifade eder, dolayısıyla yaşam sürecinin zorunlu kıldığ işlerden özgür olunan anlar, boş zaman anlamına gelmemektedir. Arendt, Karl Marx’ın dediği gibi eğlence ile doldurulduğu varsayılan bu boş zamanı, biyolojik olarak belirlenmiş çalışma döngüsü içindeki; "insanın doğal metobolizması içindeki” bir boşluk olarak değerlendirir. ${ }^{10}$

Marxist anlayışa göre sermayenin (capital) kültürel üretime sızmasıyla, kültürel ürünün giderek bir mala (commodity) dönüştügü düşünülmektedir. Yani kültürel ürünlerin, kapitalist düzende üretilen mallarla ortak noktaları bulunmaktadır. Bu benzerlikler Karl Marx’ın "kullanım değeri (use-value), değer (value), değişim değeri (exchange value), artı değer (surplus) kavramları ile açıklanabilir. Kullanım değeri, bir malın tüketicisinin işine yaramasıyla oluşturduğu kullanışlılık ya da yararlılık değeridir. İnsanların insani isteklerini tatmin etmeye bağlı olarak ölçülür. Bir malın değeri, ise yararlılığına değil sosyal olarak gerekli olan üretim süresince harcanmış emek süresine bağlıdır. Bir malın değeri ancak ekonomik olarak değişime uğraması sonucu anlaşılır. Değişim değeri ise bir malın piyasadaki başka bir mal ile pazarlanması esnasındaki oranını (Dolar, TL, Euro, vb...) ifade eder. Artı değer, işçinin işgücünden öte yaratılan değer yani kapitalist kesim tarafından serbestçe biçilebilen değerdir. Bu durumda malın kendisi alıcının yararı için değer biçecek yetkinliktedir. ${ }^{11}$

6 Dwight Macdonald, “A Theory of Mass Culture", John Storey (der.), Cultural Theory and Popular Culture: A Reader, London, New York: Routledge, 2006, s. 29.

7 Ertuğrul Turan, “Kolektif Şizofreni: Zamanın İki Yüzü”, Doğu Batı Dergisi, 22 (2003), s 197.

8 Hannah Arendth, Geçmişle Gelecek Arasında, çev., Bahadır Sina Şener, İstanbul: İletişim Yayınları, 1996, s. 243.

9 Arlı ve Çeğin, “İdeoloji Kavramının Aşınması...”, s.164.

10 Arendth, Geçmişle Gelecek Arasında, s.243.

11 Terry Lovell, “45 Cultural Production”, John Storey (der.), Cultural Theory and Popular Culture: A Reader, London, New York: Routledge, 2006, s.467. 
Marksist anlayışta kültürel ürünler kitle üretimine sokulduğunda değersiz artıklar olarak görülmektedir (bkz. Left pessimism) Kitle üretimiyle üretilen kültürel ürünler kısa sürede satılarak ve en yüksek kâr elde edilmeye çalışılmakta, ürünlerde değer ve kalite kaybı olduğu düşünülmektedir. Bu anlayışa paralel olarak kitle iletişim araçları bu süreci meşrulaştırıp normalleştirmektedir. Oysa Terry Lovell, kitle üretiminin illa ki bir değer ve kalite kaybına neden olmayacağını ifade eder. Bir malın iyi ya da kötü olduğunu yargılamaktansa sosyal bağlama odaklanılarak malların üretimi sonucunda nasıl bir kültürel yapı oluştuğu değerlendirilmelidir. ${ }^{12}$

\section{Kitle Çeviri}

Her çeviri eylemi diller ve kültürler arası bir aktarımdır; dolayısıyla ortaya çıkan çeviri ürünler kültürel ürün değeri taşırlar. Bu bağlamda; çeviri ürünler Marksist perspektife göre değerlendirilebilir. Çeviri ürünlerin aynı diğer mallar (commodity) gibi tüketicisinin iletişim ihtiyacını karşılamasından dolayı belirli bir kullanım değeri vardır. Çeviri ürün ekonomik değişime girerek ekonomik değere sahip olur. Ürünün parasal anlamda bir karşılığı olduğu için değişim değeri de mevcuttur. Çeviri, pazarında diğer çeviri ürünlerle karşılaştırıldığında zamanla alıcısının yararı için kendi değerini biçecek yetkinliğe erişir. Bu durumda çeviri ürünün artı değer kazandığ söylenebilir.

$\mathrm{Bu}$ yapı kitle çeviri yöntemi üzerinden incelendiğinde, aynı kapitalist üretim düzeninde olduğu gibi kitlesel üretimi yapılan çeviri ürünlerin diğer mallar (commodity) gibi küçük parçalara ayrılarak büyük bir işçi grubuna paylaştırıldığı görülmektedir. Dolayısıyla çeviri edimi bireysel bir eylem olmaktan çıkıp kitlesel bir eyleme dönüşmektedir. Kitle üretimi bu bağlamda seri üretime benzetilebilir. İşin küçük parçalara ayrılmasıyla kısa sürede işverenin belirlediği standartlara göre büyük oranda çeviri işi tamamlanmaktadır. Öte yandan bu üretimin kapitalist üretimden ayrılan bir noktası vardır. Üretim gerçekleşmiş olsa da bu yöntemle çeviri ürünlerin ekonomik, değişim ve artı değer kazanmadığı görülmektedir. Çünkü işi gerçekleştiren çevirmenler bu üretimi gönüllük esasına göre, karşılığında hiç bir ücret almadan yapmamaktadırlar. Dahası gönüllü çevirmenler işverenin kalite standartları doğrultusunda yalnızca çeviriyle değil terminoloji yönetimi, metni düzenleme ve yerelleştirilmiş çevirilerin gözden geçirilmesiyle de ilgilenmektedirler. ${ }^{13}$

Marksist açıdan, kapitalist düzende üretilen kültürel ürünler kısa sürede üretilip, işverenine yüksek kâr ettirse de değer ve kaliteden yoksun değersiz artıklar olarak görülmekteydi. Hâlbuki gönüllük esasına göre işleyen üretim ve denetim mekanizmasına sahip kitle çeviri yöntemiyle üretilen çeviri ürünlerinin kalitesi hakkında kesin yargıya varmak yöntemin kendine özgü yapısı gereği çok kolay değildir. Bu durumda ürünlerin iyi ya da kötü olduğunu yargılamadan üretildiği sosyal ortamını incelemekte fayda vardir. ${ }^{14}$

12 Lovell, “45 Cultural Production”, s.468.

13 Cronin, "Globalization and Translation", s.136.

14 Lovell, “45 Cultural Production”, s.468. 


\section{Kitle Çeviri Örneği: Facebook}

Bu bölümde, kitle çeviri yöntemiyle ortaya çıkan çeviri ürünlerden Facebook çevirileri incelenecektir. Kültürel ürün olarak değerlendirilebilecek Facebook çevirileri kapitalist üretime benzeyen kitlesel üretim yapısında işverenin standartları doğrultusunda kısa sürede üretilmekte ve işverenine kâr ettirmektedir. Bu bağlamda gerçekleştirilen çeviri eyleminin popüler kültür ürünü haline geldiği söylenebilir. Ortaya çıkan ürünlerin iyi ya da kötü olduğuna karar verebilmek ve çeviriyi üreten çevirmenlerin kimliğini anlamak için ürünlerin sosyal üretim şartlarına bakılmalıdır. Bu amaçla önce işverenin çevirilerin üretimi için sağladığı çalışma koşullarına, ardından gönüllü çevirmenlerin kim olduğu ve onları çeviri yapma davranışına yönlendiren etmenleri saptamak üzere anket sonuçlarına bakılacaktır.

\section{Facebook Çevirileri}

2004 yılında kurulan Facebook, kurulduğu yıl yalnızca İngilizce ara yüze sahipti. Şirket 2006'da küreselleşme atılımı yaparak tüm İngilizce konuşan ülkelerde giderek tanınmaya başladı. 2007'ye gelindiğinde tüm dünyada yaklaşık 50 milyon aktif kullanıcıya ulaştı. 2008 yılında şirket çeviri girişimi yaparak, birçok dil seçeneğini bünyesine dâhil etmeye başladı. ${ }^{15}$

Facebook'un, kitle çeviri yöntemini başarılı bir şekilde uygulayan ilk şirketlerden biri olduğu söylenebilir. Web 2. araçları sayesinde bir çeviri modülü tasarlayan Facebook, bu modül aracılığıyla kullanıcılarını işbirliği halinde topluca çeviri yapmaya davet etmiştir. Kitle çeviri yöntemi ilk aşamada 1,500 İspanyolca konuşan Facebook kullanıcılarıyla denenmiş, yalnızca dört haftada bu gönüllü kullanıcılar tüm Facebook ara yüzünü İspanyolcaya çevirmişlerdir. İspanyolca çeviri 2008 Şubat ayında piyasaya sürülmüştür. ${ }^{16}$ Ardından Almanca ve Fransızca için aynı yöntem kullanılmıştır. 2008 Nisan ayında Facebook'un toplam 22 dilde hizmet sağlar hale geldiği bilinmektedir. ${ }^{17}$ Kısa sürede uygulama başarılı olunca Facebook, kullanıcılarından gelen talepler doğrultusunda olabilecek her dili seçeneklerine eklemeye karar vermiştir. Bu amaçla kullanıcılarına bu girişime katılmaları yönünde özel mesajlar atarak, bu hareketin bir parçası olmalarını teklif ettiği bilinmektedir.

\section{Facebook Çeviri Modülü}

Facebook çeviri modülünde kaynak metin hem çevrilmek hem de çeviri kalitesi oylanmak üzere tasarlanmıştır. Çevirmen niteliğine sahip Facebook üyeleri, Facebook profillerine "çeviriler" uygulamasını indirdikten sonra bu çeviri platformu erişime açılır. Modülün kullanıcı dostu ve basit bir yapıya sahip olduğu söylenebilir. Çevrilecek metin küçük segmentler halinde kullanıcıya sunulmaktadır. Üye çevir-

15 Justin Smith, InsideFacebook, 19 Ağustos 2008, http://www.insidefacebook.com/2008/08/19/mappingfacebooks-growth-over-time (Erişim 1 Aralık, 2014).

16 Micheal Arrington, Techcrunch. "Facebook Turns 1,500 Users Into Spanish Translation Slaves". https:// techcrunch.com /2008/02/07/facebook-turns-1500-users-into-spanish-translation-slaves (Erişim 5 Aralık, 2014).

17 Nick Burcher, Nick Burcher, 2008, http://www.nickburcher.com/search?q=facebook+translation (Erişim 7 Aralık 2014). 
menler, kaynak metnin çevirisini yaparken, modül içerisinde metnin bağlamı hakkındaki açıklamayı okur, terminolojiye dair sözlüğe bakar, varsa metnin önceki çevirilerini görebilirler. Çevirmenler, yeni çeviri önerisi yapabildikleri gibi var olan çevirileri oylayarak da çevirilere katkı sağlayabilirler. En çok oylanan çeviri daha sonra yayınlanmak üzere sisteme kaydolur.

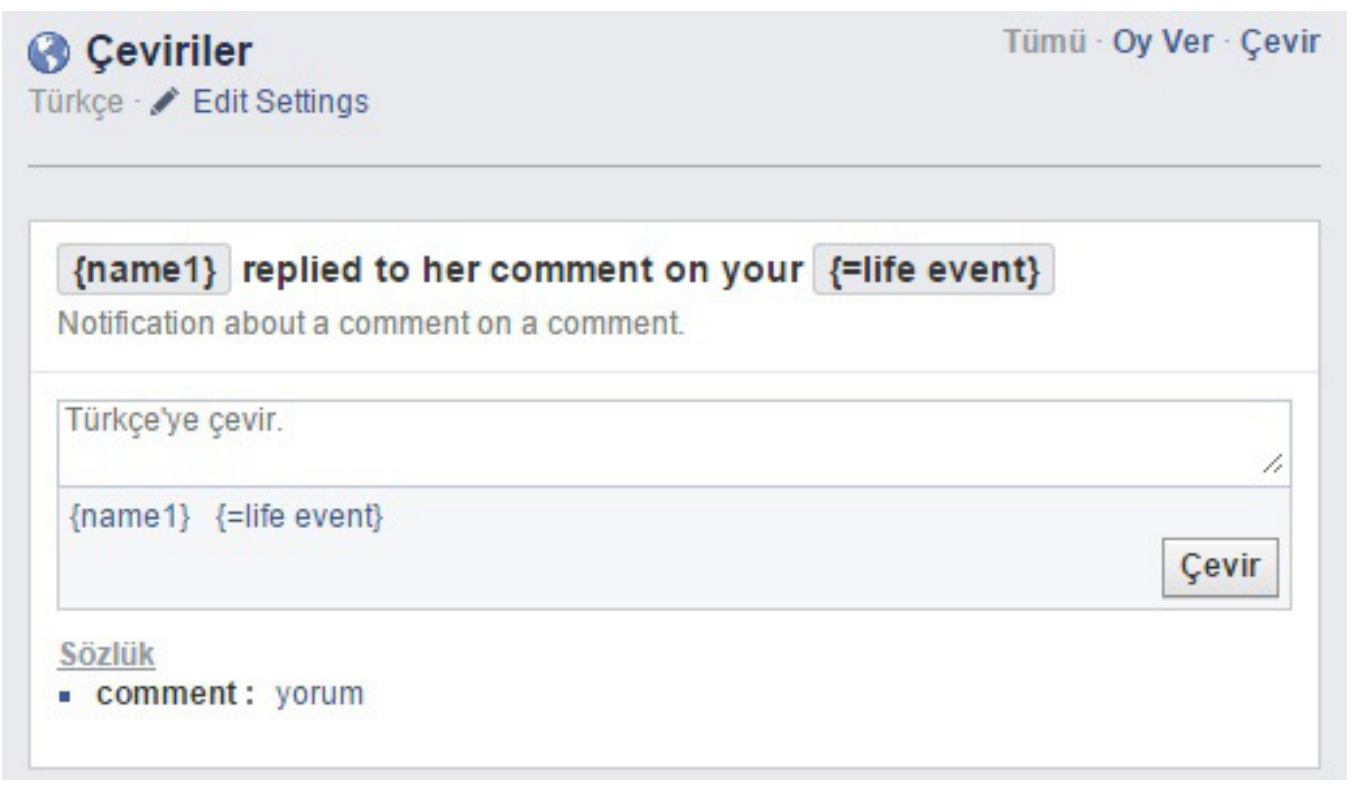

Şekil 1.

Facebook üretilen çevirilerde kalite standartlarını sağlamak adına üye çevirmenler için "Faydalı Çeviri Bağlantıları" başlığı altında çeviriye yardımcı kılavuzlar sunmaktadır. Çevirmenler ihtiyaç duyduklarında çeviri sistemine dair merak ettiklerini bu kılavuzlardan öğrenebilirler.

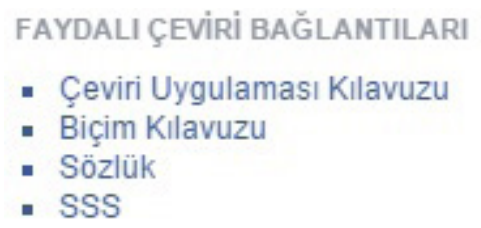

Şekil 2.

Üye çevirmenler, çeviri eylemine katılmak için yalnızca çeviri yapmak zorunda değildir. Çeviri önerisi yapmak kadar var olan çevirileri oylama da uygulamanın işleyişi adına önemli bir katkıdır. Oylama sisteminde kaynak metin verilerek var olan tüm alternatif çeviriler sıralanır, çevirmenden en uygun çeviriyi oylaması istenir. 


\section{Çeviriler}

Türkçe Edit Settings

\begin{tabular}{l} 
Get instant updates on your phone \\
Email subject \\
Telefonunuza anlık güncellemeleri alın \\
Telefonunuzda anlık güncellemeleri alın. \\
Telefonunuzla anlık güncellemeleri alın. \\
\hline Telefonunuzdan anlık güncellemeleri edinin \\
$\checkmark \checkmark$ \\
\hline
\end{tabular}

Şekil 3.

Facebook, yapılan çevirileri çeviri modülünde simgesel olarak ödüllendirmek için bir arayüz eklemiştir. Üye çevirmenler, yaptıkları çeviriler aracıllğıyla bu ödülleri kazanır, çok ödül kazandıkları takdirde liderlik sıralamasına girerek çeşitli unvanlar (mayor, blogger, typesetter) kazanırlar.

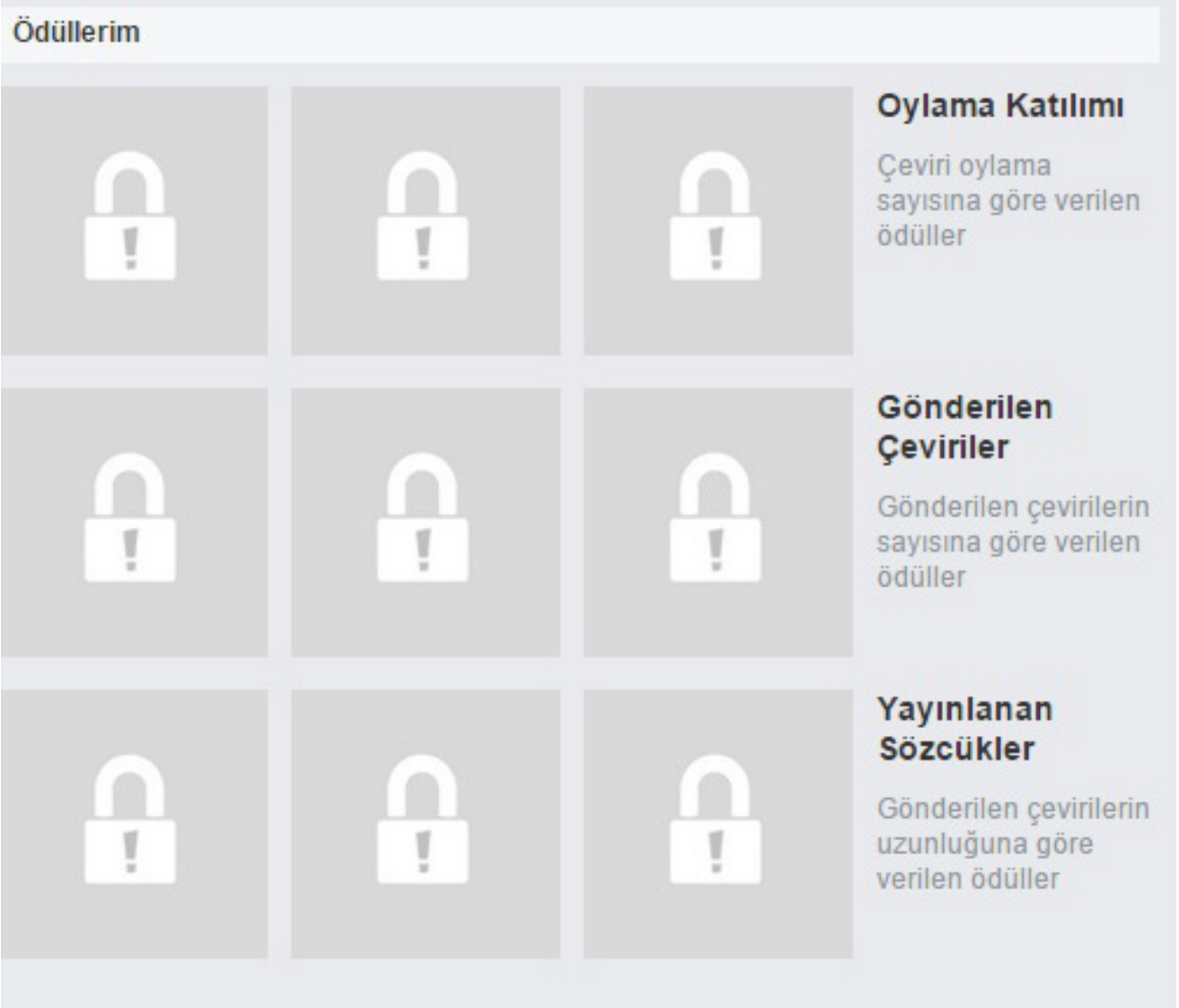

Şekil 4. 


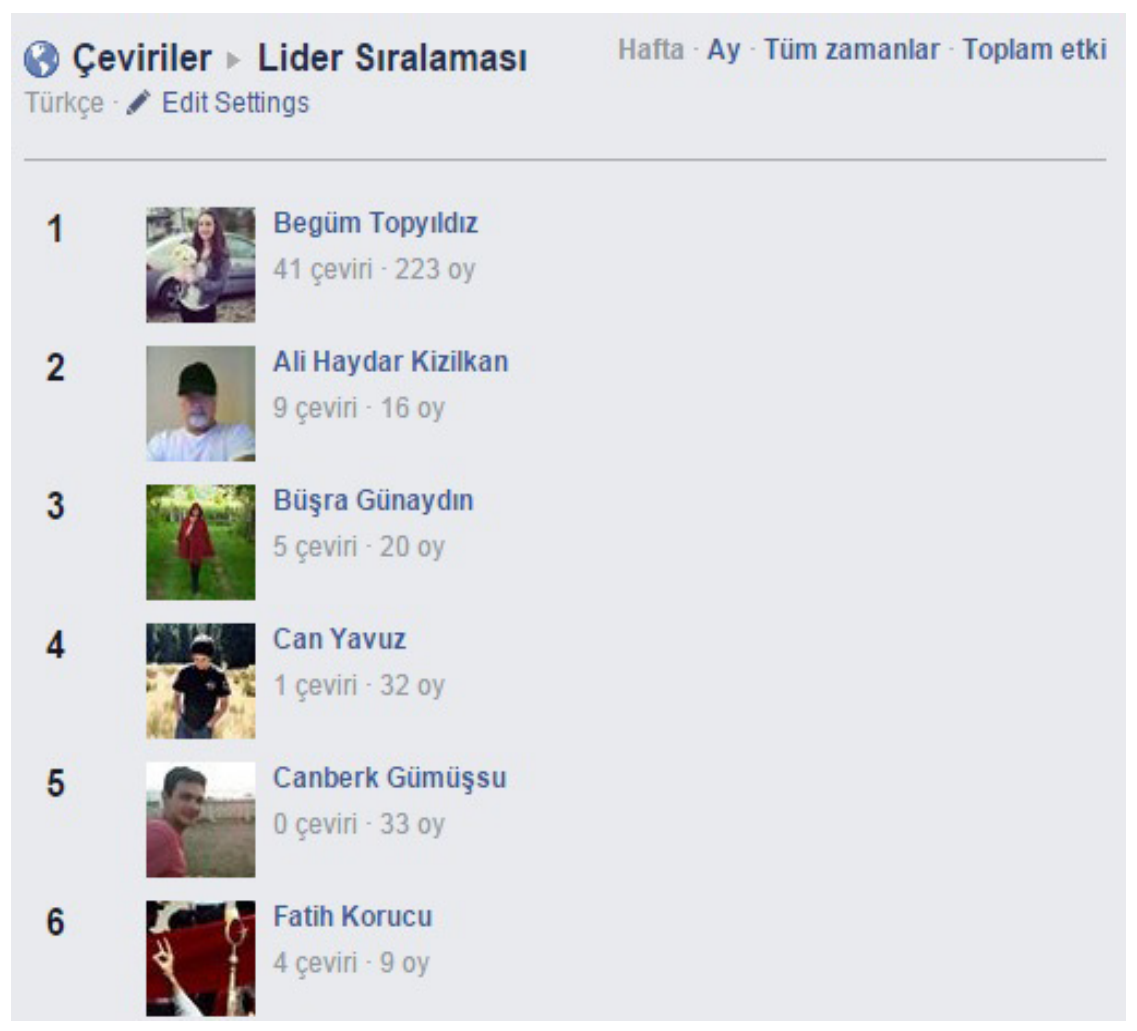

Şekil 5.

Çeviri modülünde, üye çevirmenler, katkı ve etki başlığı altında çeviri eylemine ne derece katkıda bulundukları bilgisini görebilirler. Facebook üyelerin daha fazla katkıda bulunmaları, daha çok çeviri yapmaları ve arkadaşlarını bu uygulamadan haberdar etmeleri için bu bölümde uygulamanın reklamını yapar.

\section{KATKILARIN (TÜRKÇE)}

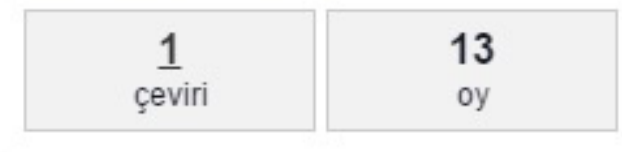

ÖDÜLLERIN (TÜRKÇE) Tümünü Gör

Daha fazla ödül almak için çevir ve oyla!

\section{ETKi}

Facebook'un çevrilmesine yardım ederek,

Facebook'u Türkçe kullanan 370

arkadașına yardımcı oluyorsun.

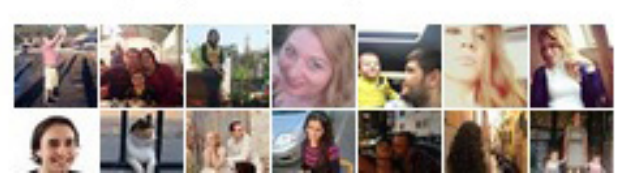

Şekil 6. 


\section{Facebook Gönüllü Çevirmenler Anketi Analizi}

Kitle çeviri yöntemiyle üretilen çevirilerin gönüllü çevirmenlerinin kim olduğu ve onları çeviri yapma davranışına yönlendiren etmenleri saptamak üzere, çeviri modülünde yer alan liderlik sıralamasına girmiş çevirmenlere 16 soruluk bir anket uygulanmıştır. 50 kişiye anket yönlendirilmiş, toplam 20 kişi anketi eksiksiz yanıtlamıştır. Değerlendirmeler bu grupla sınırlıdır. Anket kapsamında, çevirmenlere sorulan sorular şunlardır:

- Cinsiyetiniz?

- Yaşınız?

- Eğitim durumunuz?

- Kaç yıldır Facebook kullanıcısısınız?

- Günde en az kaç kere Facebook’a girersiniz?

- Facebook üyelerinin Facebook’u Türkçeye çevirdiğini nereden duydunuz?

- Kaç yıldır Facebook ara yüzünü Türkçeye çeviriyorsunuz?

- Facebook çevirisi haricinde profesyonel olarak (para kazanma) çeviri yapıyor musunuz?

- Kendinizi "çevirmen” olarak tanımlayabilir misiniz?

- Facebook'u gönüllü olarak çevirmenizdeki amaç nedir?

- Sizce Facebook'ta çeviri yapma popüler bir aktivite midir?

- Facebook çevirilerini kaliteli buluyor musunuz?

- Gönüllü olarak çeviri yaptığınız başka internet siteleri var mı?

- Facebook'un çeviri karşıllğında verdiği unvanlara (Mayor, Blogger, Typesetter) hiç sahip oldunuz mu?

- Facebook'un çeviri ve oylama sistemi sizce kolay mı?

- Facebook çeviri tartışma gruplarını aktif kullanıyor musunuz? (Facebook Translators Team, Facebook Translation Türkçe)

Ankete katılanlardan yarısı kadın; yarısı erkektir. Katılımcılardan, 13 kişi 19-29 yaş aralığında, 5 kişi 30-49, 1 kişi 0-18, 1 kişi 50-70 yaş aralığındadır. 13 kişi lisans mezunu, 6 kişi yüksek lisans, 1 kişi de lise mezunudur. 13 kişi 5 ile10 yıldır Facebook kullanırken 5 kişi 1-5, 2 kişi 10 yıldan fazla Facebook üyesidir. Kişilerden 11'i Facebook'un kitle çeviri yöntemiyle çevrildiğini kendisi araştırıp bulduğunu, 5’i bunu Facebook reklamlarından öğrendiğini, 2'si Facebook çeviri gruplarında gördüğünü, 3'ü de arkadaş tavsiyesiyle bu bilgiye ulaştığını ifade etmiştir. Katılımcılardan 13'ü Facebook çevirileri haricinde profesyonel olarak çeviri yapmakta, 7’si yapmamaktadır. 11 kişi 0-2 yıldır Facebook’u Türkçeye çevirirken, 9 kişi 2-4 yıldır Facebook için çeviri yapmaktadır. Katılımcılardan, 14'ü kendini çevirmen olarak tanımlamakta 6’sı çevirmen olmadığını düşünmektedir. Kişilere, birden fazla yanıt verebildikleri Facebook'u Türkçeye çevirme amaçları sorulduğunda, \%22,22'yle katılımcıların çeviri eylemini bir hobi olarak gördükleri, \% 17,93'yle çeviri yeteneğini geliştirmek istedikleri, \%15,87’yle Türklerin Facebook'u Türkçe kullanmasını sağlamaya çalıştıkları, \% 9'yla Facebook'un bir parçası olmak istedikleri görülmektedir. Katılımcılardan 17'si Facebook çevirisi yapma eylemini popüler olarak değerlendirmemekte, 3 kişi popüler olduğunu düşünmektedir. 13 kişi Facebook çevirilerini kaliteli bulurken, 7’si 
kalitesiz bulmaktadır. 12 kişi Facebook haricinde başka siteler için gönüllü çeviri yaparken, 8 kişi yalnızca Facebook için gönüllü çeviri yapmaktadır. Facebook’un sağladığı unvanlara katılımcıların yarısı sahip olduğunu ifade ederken diğer yarısı sahip olmadığı yanıtını vermiştir. 18 kişi Facebook oylama sistemini kolay olduğunu düşünürken, 2 kişi kolay olmadığı yanıtını vermiştir. Son olarak katılımcılara Facebook çeviri tartışma gruplarını ne derece aktif olarak kullandıkları sorulmuş, 13’ü olumsuz, 7'si olumlu yanit vermiştir.

\section{Anket Analizi}

Kitle çeviri yöntemiyle üretilen çevirilerin gönüllü çevirmenlerinin kim olduğu ve onları çeviri yapma davranışına yönlendiren etmenlerin ne olduğu 20 kişilik katılımcı grubuna 16 soruluk anket uygulanarak tespit edilmeye çalışılmıştır. Anket değerlendirmeleri yalnızca bu grubu kapsasa da araştırmanın sorunsallarına yönelik önemli noktaları açı̆̆a çıkarmaktadır.

Anket genel olarak değerlendirildiğinde katılımcıların çift kimlikli yapısı dikkat çekmektedir. Facebook çevirilerini yapanlar hem çevirmen hem de Facebook kullanıc1larıdır; yani gönüllü çevirmenler hem çeviri eylemini gerçekleştirdikleri için işçi hem de bu uygulamadan yararlandıkları için müşteri konumundadır. Üye çevirmenlerin çoğunluğunun profesyonel olarak hali hazırda çeviri yaptıkları görülmektedir, buna ek olarak birçoğu zaten kendini çevirmen olarak tanımlamaktadır. Bu bağlamda, çeviri işini büyük oranda profesyonellerin yönlendirdiği söylenebilir. Kitlesel üretimle ortaya çıkan çeviri ürünlerin kalitesi değerlendirildiğinde işverenin bu noktada oylama sistemi kurarak kaliteyi garanti altına aldığı görülmektedir. Dolayısıyla ortaya çıkan kültürel ürün olarak değerlendirilen bu çevirilerin tam anlamıyla kaliteden yoksun, değersiz olduğu söylenemez, anket sonuçlarına göre katılımcıların çoğu da bu görüşü desteklemekte, oylama sistemini olumlamaktadırlar.

Anket sonuçları kitle çeviri yöntemiyle çeviri yapma eyleminin popüler kültür ürünü haline geldiğini doğrulamıştır. Katılımcıların büyük çoğunluğu, çeviri işini hobi olarak gördüklerini bu yüzden Facebook'u çevirdiklerini ifade etmiştir. Hobi kavramı, boş zaman kavramı ile ilintili bir kavramdır. Nitekim popüler kültürle yaratılmış bir olgudur. Eğlenmek ve tüketmeye yönelik kurgulanmış anlardır. ${ }^{18}$ Çevirmenler, Facebook'a girerek boş zaman harcamakta, çeviri yaparak sistemin işlemesine katkıda bulunmaktadırlar. Gönüllü çevirmenlerin çeviri yapmalarının altında yatan diğer önemli etmenler Facebook'un Türkçe kullanılmasını istemeleri ve Facebook'un bir parçası olma istekleridir. Bu noktada işverenin yine popüler kültür zeminini kullanarak reklam yoluyla bu istekleri üyelerinin bilinçaltına yerleştirdiği söylenebilir. Görüldüğü üzere, Facebook çeviri uygulamasını kurgularken yine popüler kültürü kullanarak bu uygulamayı pazarlamakta ideolojik bir içerik yaratarak kitlelerin bilinçaltına hitap etmektedir (Bkz. Bölüm 2/Şekil 6).

\section{Sonuç}

Bu çalışmada, kitle çeviri yöntemiyle çeviri eyleminin nasıl bir dönüşüm içine girdiği değerlendirilmeye çalışılmıştır. Kitle çeviri yöntemiyle kitlesel üretimi yapılan çeviri 
eyleminin giderek popüler kültür ürünü haline geldiği görülmektedir. Kültürel ürün olarak değerlendirilebilecek Facebook çevirileri kapitalist üretime benzeyen kitlesel üretim yapısıyla işverenin standartları doğrultusunda kısa sürede üretilmekte ve işverenini az maliyetle kâr ettirmektedir. Popüler zeminde üretilen bu çevirilerin kalitesinin iyi ya da kötü olduğuna karar verebilmek ve çeviriyi üreten çevirmenlerin kimliğini anlamak için ürünlerin sosyal üretim şartlarına bakılmıştır. Gönüllü çevirmenlerin çoğunluğunun profesyonel olarak çeviri yaptığı tespit edilmiştir. Dolayısıyla, çeviri işini büyük ölçüde profesyoneller yönlendirmektedir. Çift kimlikli niteliğe sahip gönüllü çevirmenler hem çeviri eylemini gerçekleştirdikleri için işçi hem de bu uygulamadan yararlandıkları için müşteri konumundadır. Kitlesel üretimle ortaya çıkan çeviri ürünlerin kalite değerinin, işverenin tasarladığı oylama sistemiyle korunduğu görülmektedir. Neticede, ortaya çıkan kültürel ürünlerin tam anlamıyla kaliteden yoksun, değersiz olduğu söylenemez.

\section{Kaynakça}

Arendt, Hannah. Geçmişle Gelecek Arasında. Çev., Bahadır Sina Şener. İstanbul: İletişim Yayınları, 1996: 243-244.

Arlı, Alim ve Güney Çeğin. “İdeoloji Kavramının aşınması ve Pierre Bourdieu’nün Kuramsal Seçenekleri”. Doğu Batı Dergisi, 28 (2004): 163-179.

Arrington, Michael.Techcrunch. "Facebook Turns 1,500 Users Into Spanish Translation Slaves”. Erişim 5 Aralık, 2014. https://techcrunch.com/2008/02/07/ facebook-turns-1500-users-into-spanish-translation-slaves/ İngilizce

Burcher, Nick. 2008. Nick Burcher. Erişim 7 Aralık, 2014. http://www.nickburcher. $\mathrm{com} /$ search? q=facebook+translation.

Cronin, Micheal. "Globalization and Translation” Handbook of Translation Studies. Gambier ve Van Luc Doorslaer. Amsterdam: John Benjamins Publishing, 2010: 134-140.

Howe, Jeff. Wired.14 Temmuz 2006. Erişim 30 Kasım, 2014. www.wired.com/wired/ archive/14.06/crowds.html.

Lovell, Terry. "45 Cultural Production". Cultural Theory and Popular Culture: A Reader John Storey. Pearson Education, 2006: 467-468.

Macdonald, Dwight. "A Theory of Mass Culture". Cultural Theory and Popular Culture: A Reader, John Storey. London amd NewYork: Routledge, 2006: 29.

Smith, Justin. InsideFacebook.19 Ağustos 2008. Erişim 01 Aralık, 2014. http://www. insidefacebook.com/2008/08/19/mapping-facebooks-growth-over-time/.

Turan, Ertuğrul. “Kolektif Şizofreni: Zamanın İki Yüzü”. Doğu Batı Dergisi, 22 (2003): 197-207. 


\title{
A Study on Crowdsourcing Translation in Social Media
}

\author{
EZGİ KESKIN GAGA
}

\begin{abstract}
This research aims to examine the Crowdsourcing Translation that is supposed to become a popular action recently in the example of "Social Media Translation" in Turkey. The main problematic of the study is translation (as an action) becoming popular culture material through crowdsourcing translation; the quality of the translations produced in that popular ground and identity of translators translating. Within the research, by examining one of the social media website called Facebook, 16 question survey was conducted to volunteer translators contributing Facebook Turkish translation. The results of the evaluation have emerged in the framework of the implementation of the survey. The evaluations are limited to the groups surveyed. In the first part, the position of crowdsourcing in popular culture is studied and in the second part "crowdsourcing translation" is analyzed. At the end of the study, it has seen how translation action transformed through crowdsourcing translation and become mass production ultimately and it seems to become a popular cultural product gradually.
\end{abstract}

Keywords: Crowdsourcing Translation, Social Media Translation, Volunteer translation/ translator. 